
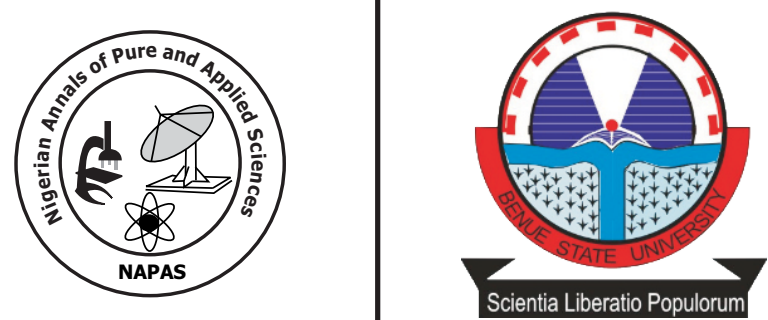

\title{
Comparative Nutritional Assessment of Products made from Fresh and Dried Tiger Nut sold in Makurdi Metropolis
}

\author{
Ogo, A..$^{1^{*}}$, Kparev $\mathrm{M}^{2}$ Amali E.0.0. ${ }^{1}$, Efiong E.E. ${ }^{3}$, Obochi G. $0^{1}$. \\ ${ }^{1}$ Department of Biochemistry, Benue State University, Makurdi, \\ ${ }^{2}$ Department of Biochemistry, Federal University of Agriculture, Makurdi \\ ${ }^{3}$ Department of Biochemistry, Federal University Lafia \\ *Corresponding author:oogo@bsum.edu.ng. +2348033206646
}

\section{Abstract}

Tiger nut (cyperus esculentus) is taken as optional snacks mainly in its fresh form owing to poor availability of nutritional information on the composition of other forms such as the dried form. To address this gap, this study was designed to assess the nutritional composition of fresh and dried tiger nut milk by determining the proximate composition and amino acid profile using standard analytical methods. The samples were grouped into A, B, C and D representing milk and powder made fresh tiger nuts, as well as milk and powder made from dried tiger nuts respectively. Results of proximate analysis for the samples showed variation in the constituents with highest amounts of carbohydrate found in the fresh form except for the powder product from dried form, which has equivalent amount to those of fresh tiger nut. Amino acid profile generally showed reasonable amounts in all the samples with products made from fresh tiger nut having higher values, while milk and powder products of dried tiger nut contain more of the other nutrient constituents than the fresh one. These findings are key to optimizing nutritional value of tiger nut products made from different forms, thus, is helpful in guiding nutrition and dietetic advice in clinical setting to supplement other choices in resolving cases of protein energy malnutrition and other forms of malnutrition. In addition, the nutrient composition of tiger nut makes it ideal as a valuable substitute for conventional cow milk and other milk sources, which have become unaffordable to people with low economic empowerment, pariticularly among developing nations.

Key word: Tiger nut, proximate compostion, amino acid profile, Nutritional value 


\section{Introduction}

Tiger nut (Cyperus esculentus) belongs to the division Magnoliophyta, classlilliopsida order and cyperaceae family, which produces rhizomes from the base of the tubers (Salau et al., 2013, Gambo et al., 2014). Dried ground tubers are used in coffee and chocolate drinks. Tiger nut milk originated from Spain where it is known as chufa de horchata, but it is commonly called kunnu aya in northern Nigeria (Bamishaiye and Bamishaiye, 2011). It is an underutilized tuber of but can used in the production of milk which is inexpensive, healthy and rich in several micronutrients and amino acids (reviewed by Gambo et al., 2014).

The nutritional composition of this tuber qualifies it as a good substitute for the conventional diary milk that has gone beyond the reach of many owing to economic downturn, particularly in the developing nations. Research has shown that many products derived from this tuber contain essential nutrients necessary for both child and adult development in addition to macromolecules such as starch and oil (Jing et al., 2016). For instance, it has been reported to contain essential minerals required by the body as accessory factors to numerous enzymes that participate in a plethora of cellular metabolic activities as well as antioxidants (Abaejoh et al., 2006, Ogunlade et al., 2015). It is also healthy and rich source of nutrients such as carbohydrates, vegetable fat, protein, fiber, vitamins, minerals, energy and some digestive enzymes such as catalase, lipase and amylase (Adejuyitan, 2011). The high cost of conventional milk in developing countries, particularly among low income earners has led to the sourcing of alternatives from plant sources. An inexpensive substitute in the form of a milk or beverage made from locally available plant foods, high in protein, with satisfactory quality milk could play an important role to reduce protein malnutrition, and also contribute in improving nutrition of farm animals when such products can be used to supplement their feeds.

Tiger nuts have long been recognized for their nutritional benefits as they have a high content of soluble glucose, and oleic acid, along with high energy content (starch, fats, sugar and protein) (Bibek, 2001). They are rich in minerals such as phosphorus and potassium calcium, magnesium and iron necessary for bones, tissue repair, muscles and for body growth and development and rich in vitamins $\mathrm{E}$ and $\mathrm{C}$. (Oladele \& Aina 2007). Sugar-free tigernut milk is suitable for diabetic people and also helps in weight control due to its content of carbohydrates with a base of sucrose and starch, and its high content of Arginine, a precursor of nitric acid which helps the bone to expand (bixquert-jimenze, 2003).and liberates the hormones that produces insulin. Tiger nuts are recommended for those who suffer from indigestion, flatulence and diarrhea because it provides digestive enzymes like the catalase, lipase and amylase (Bixquertjimenze, 2003). The high content of Oleic acid has positive effect on cholesterol, preventing heart attacks, thrombosis and activates blood content of soluble glucose. It has advantage of not containing lactose casein, much sugar or cholesterol and is therefore an ideal milk for people who do not tolerate gluten or cow's milk (Belewu et al; 2006).

Tiger nut, a non-conventional tuber is consumed fresh or dried; raw or toasted mainly as passing snack but the extent to which the choice of a particular form is influenced cannot be ascertained owing to lack of comparative compositional information of this food item to prospective consumers. Thus, this present study was aimed at providing that missing link by studying different products that can be made from tiger nut either in its fresh or dried form. This information is of utmost importance in terms of maximizing the full potential of tiger nut for food or therapeutic purposes.

\section{Materials and Methods \\ Collection of Samples}

Fresh and dried tiger nuts was purchased from Wadata market in Makurdi Benue State, Nigeria. Both fresh and dried samples were sprayed on a flat basket to allow for easy sorting of damaged ones, stones and other forms of impurities. Thereafter, the fresh and dried nuts were poured into a basin, washed to remove dust from the body of the nuts. The samples were then divided into two equal portions in each case and used for the preparation of milk and powder.

\section{Preparation of milk and powder from tiger nut}

The measured portion was soaked in water for $24 \mathrm{~h}$, then blended with a Kenwood blender. $100 \mathrm{~g}$ of the blended sample was weighed into a $500 \mathrm{~cm}^{3}$ beaker and $200 \mathrm{~cm}^{3}$ of deionized water was added to the beaker. The mixture was homogenized and sieved using a Muslin cloth to filter the milk product, which was immediately refrigerated at $4^{\circ} \mathrm{C}$ for further analysis. For powdered product, the blended sample was spread on a clean paper and dried at room temperature for two days after which it was packaged in a labelled cellophane for further use. The milk and powder samples from fresh tiger nut were labelled A and B while the milk and powder samples from dried tiger nut were labelled $C$ and $D$ respectively. 


\section{Determination of Proximate composition of samples}

Proximate analysis on the sample was carried out soon after the sample were prepared to avoid any loss in the quality of the preparations. Moisture content, carbohydrate, protein, crude fibre, ash and protein contents were determined following standard procedures for proximate analysis of food items (AOAC, 2005).

\section{Determination of amino acid profile of samples}

Amino acid composition was determined according to methods described elsewhere (Ogo et al., 2018) using an Applied Biosystems PTH Amino Acid Analyzer (model120A PTH; Applied
Biosystems, USA). Tryptophan was separately determined since it is susceptible to acid hydrolysis, a method used to release other amino acid before being loaded onto the analyzer.

\section{Statistical analysis}

The analysis was carried out in duplicate for all determinations The statistical tool (SPSS software version 18.0) was used for the analysis of variance (ANOVA) and the difference in mean of the samples were then compared after the level of significance was set at $\mathrm{p}<0.05$.

\section{Results}

Table 1: Proximate composition of tiger nut milk and powder

\begin{tabular}{lllllll}
\hline \multicolumn{7}{c}{ Proximate constituent (\%) } \\
\cline { 1 - 4 } Sample & Protein & Fat & Fibre & Ash & Moisture & Carbohydrate \\
\hline A & $7.13^{\mathrm{a}}$ & $12.12^{\mathrm{b}}$ & $0.24^{\mathrm{b}}$ & $0.46^{\mathrm{b}}$ & $65.03^{\mathrm{a}}$ & $2.71^{\mathrm{b}}$ \\
B & $7.99^{\mathrm{a}}$ & $25.30^{\mathrm{a}}$ & $1.22^{\mathrm{b}}$ & $1.03^{\mathrm{b}}$ & $61.32^{\mathrm{a}}$ & $3.11^{\mathrm{b}}$ \\
C & $4.14^{\mathrm{b}}$ & $10.19^{\mathrm{b}}$ & $20.53^{\mathrm{a}}$ & $5.81^{\mathrm{a}}$ & $20.63^{\mathrm{b}}$ & $38.69^{\mathrm{a}}$ \\
D & $7.30^{\mathrm{a}}$ & $24.25^{\mathrm{a}}$ & $0.24^{\mathrm{b}}$ & $0.46^{\mathrm{b}}$ & $65.03^{\mathrm{a}}$ & $2.71^{\mathrm{b}}$ \\
\hline
\end{tabular}

Values with different superscript along the columns are significantly different $\mathrm{p}<0.05$
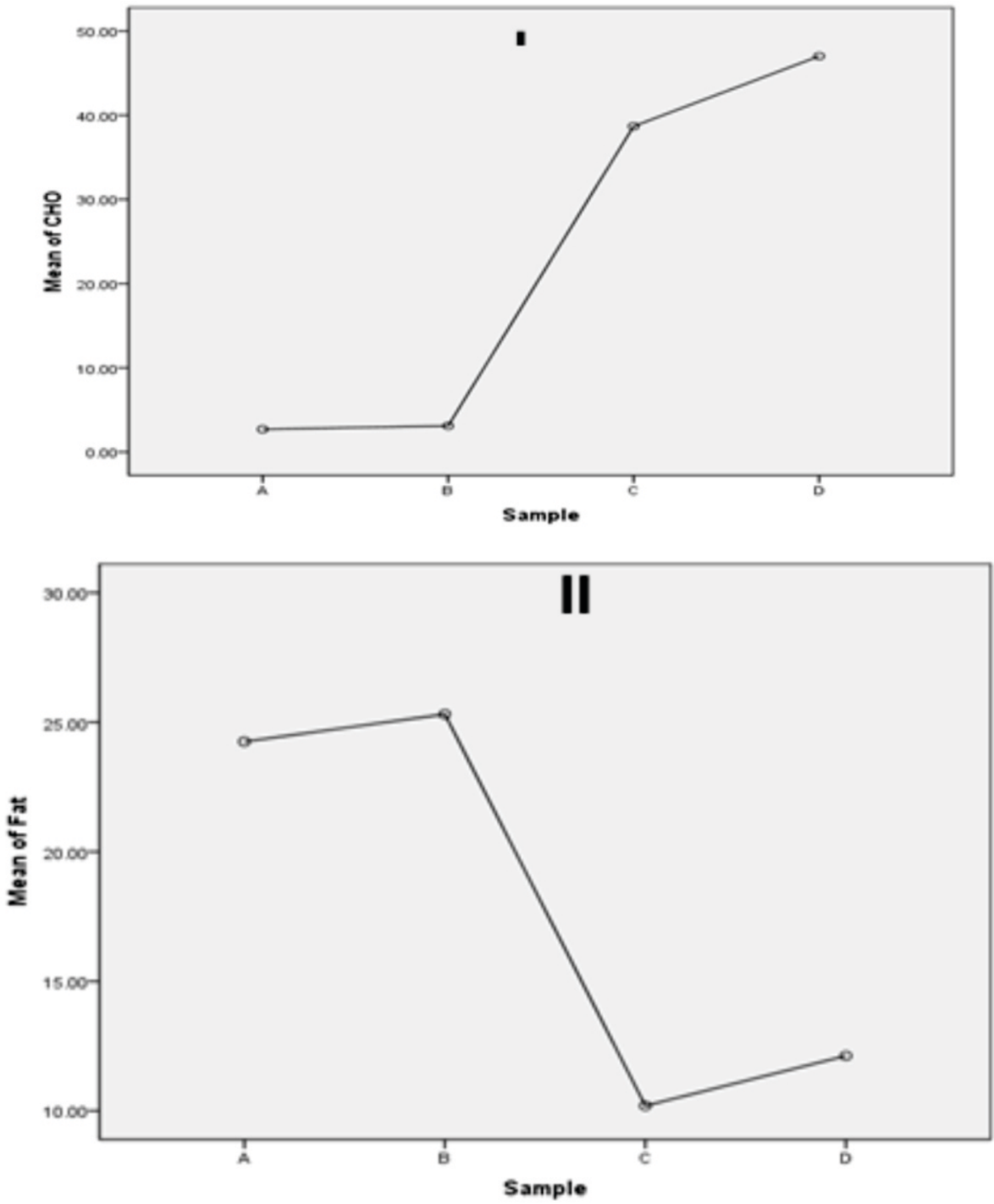

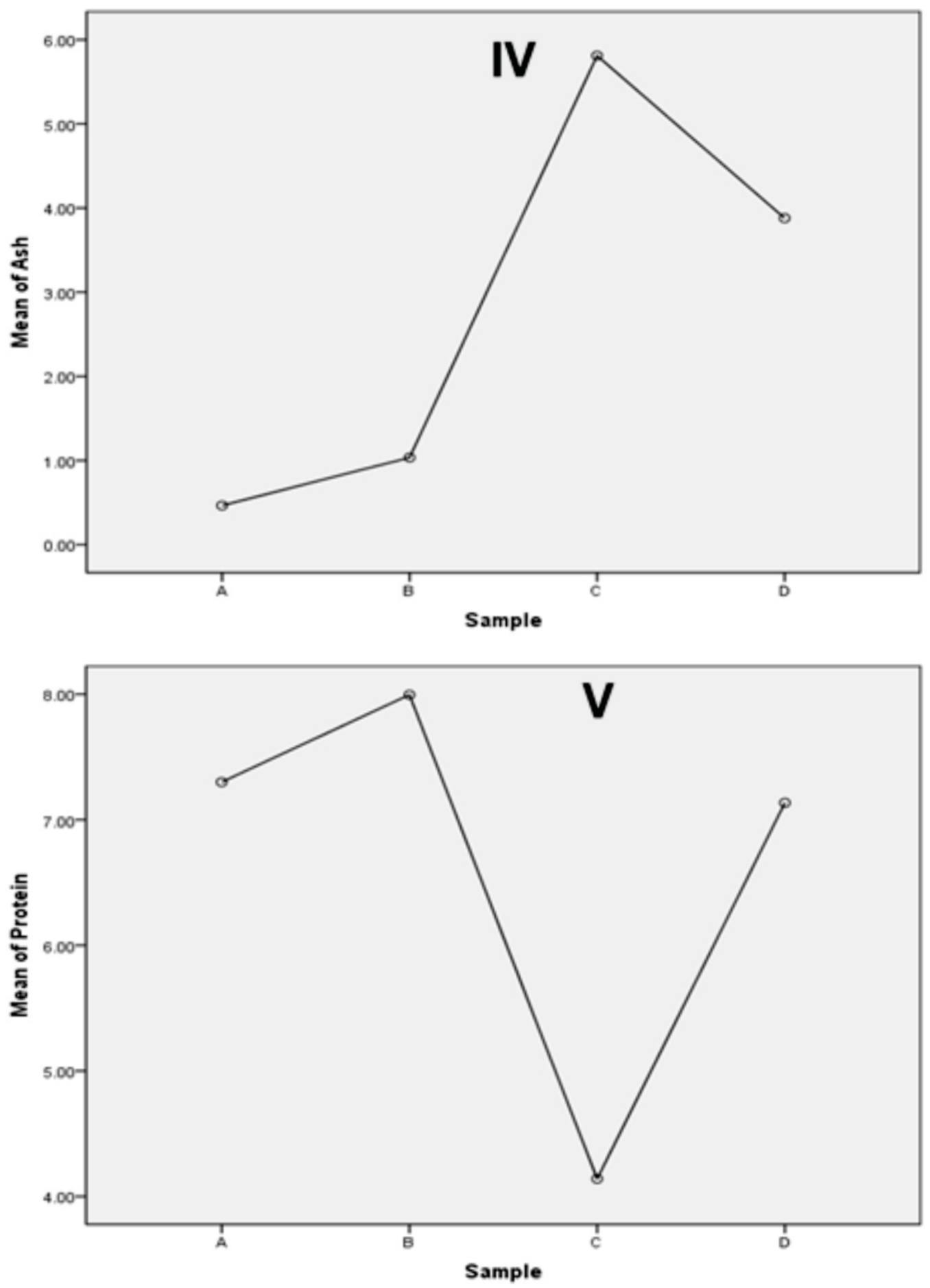

Figure 1: Proximate constituents of tiger nut products. The mean values for carbohydrate, fibre, fat, ash and crude protein are as indicated in the graphs labeled I, II, III and V respectively. Letters A and B represent milk and powder samples from fresh tiger nuts while letters $C$ and D represent milk and powder samples from dried tiger nuts.

Table 2: Essential amino acid composition of milk and powder from tiger nuts

\begin{tabular}{lllll}
\hline & Sample & & & \\
\hline Amino acid & A & B & C & D \\
Leucine & $6.12^{\mathrm{a}}$ & $3.94^{\mathrm{b}}$ & $5.69^{\mathrm{c}}$ & $7.12^{\mathrm{a}}$ \\
Lysine & 2.94 & 3.02 & 2.41 & 4.83 \\
Isoleucine & 4.06 & 1.83 & 3.41 & 3.96 \\
Phenylalanine & 2.84 & 2.39 & 2.48 & 2.48 \\
Tryptophan & 0.97 & 1.00 & 0.84 & 1.13 \\
Valine & 3.59 & 3.07 & 3.22 & 3.51 \\
Methionine & 1.28 & 0.91 & 1.02 & 1.18 \\
Threonine & 2.80 & 2.72 & 2.50 & 3.00 \\
Arginine & $5.07^{\mathrm{a}}$ & $3.87^{\mathrm{b}}$ & $4.30^{\mathrm{c}}$ & $4.73^{\mathrm{c}}$ \\
\hline
\end{tabular}


Table 3: Non-essential amino acid composition of milk and powder from tiger nuts

\begin{tabular}{lllll}
\hline & & \multicolumn{2}{c}{ Sample } & \\
\cline { 3 - 4 } Amino acid & $\mathbf{A}$ & B & C & D \\
\hline Proline & 3.14 & 2.03 & 2.84 & 3.25 \\
Tyrosine & 2.92 & 1.72 & 2.75 & 2.92 \\
Histidine & 1.88 & 1.79 & 1.60 & 2.02 \\
Cysteine & 0.72 & 0.72 & 0.55 & 1.21 \\
Alanine & 3.60 & 3.49 & 3.26 & 3.70 \\
Glutamic acid & $12.33^{\mathrm{a}}$ & $8.02^{\mathrm{b}}$ & $11.18^{\mathrm{a}}$ & $13.24^{\mathrm{a}}$ \\
Glycine & 2.61 & 3.02 & 2.40 & 2.51 \\
Serine & 3.99 & 2.57 & 3.62 & 4.00 \\
Aspartic acid & $6.32^{\mathrm{a}}$ & $5.70^{\mathrm{b}}$ & $6.29^{\mathrm{a}}$ & $7.19^{\mathrm{a}}$ \\
\hline
\end{tabular}

\section{Discussion}

Tiger nut milk is a refreshing vegetable drink which is prepared mainly with tiger nut, sugar and water. It can serve as a substitute for traditional cow milk with a natural sweet taste. The result of proximate analysis of tiger nut milk revealed that the sugar level of tiger nut milk is relatively low similar to those found by other report (shaker et al., 2009), indicating that this food product can be used by diabetic patients. Results of carbohydrate content showed a significant difference $(p<0.05)$ between milk and powder products of tiger nut derived from the dried form with the powder product containing relatively higher percentages. These results agree with those of previous reports (Adejuyitan, 2009; Adejuyitan et al., 2011; Elena et al., 2012 \& Gambo et al., 2014), who determined the physicochemical properties and composition of tiger nut and its potential for health use. However, the dried form of tiger nut is more ideal to optimize carbohydrate content in this food item, particularly in the management of some metabolic disorders associated with imbalance sugar metabolism.

The crude fibre content obtained from this study is generally low and does not agree with values obtained from a study on the chemical composition of tiger nut (Adel, et al., 2015). The difference may be occasioned by the geographical differences and methods of farming of the product considered in these studies. However, a significant amount of fibre found in milk from dried tiger nuts may make it suitable for use as many reports have documented the usefulness of dietary fibre as antitumorigenic and hypocholesterolaemic agent and may thus be recommended for use by people with fat related problems (Olagbemide et al., 2015). The result of ash content showed significantly higher values $(\mathrm{p}<0.05)$ for products from dried tiger nut compared to fresh form. Ash content of food is an indication of mineral nutrients that may be present in such food item. Adejuyitan (2011) also found significant amount of minerals in tiger nut flour, thus it may be necessary to also evaluate the mineral content in order to ascertain if the ash content value correlate with expected high mineral contents.

An expected result is the higher percentage of protein found in fresh tiger nuts compared to the dried form, which agrees with many reports such as those of Oladele et al. (2007) and, Adel et al. (2015). The finding that the dried tiger nut contain higher amounts of proteins than the fresh products was somewhat unexpected. However, some food items could have increased amounts of certain nutrients after being processed. This observation is thus consistent with the findings of Akanbi et al., 2004, who found that dried slices of tomatoes retained more of an antioxidant lycopene when compared with fresh form, suggesting that the process of drying is after all not detrimental to the nutritional composition of certain food items. The results of protein content of powdered product of dried tiger nuts appeared to have a competitive value with those of the fresh forms, and motivated investigation into the amino acid profile of the samples.

The result of amino acid composition revealed that, tiger nut is rich in essential amino acids such as leucine, isoleucine, lysine, valine and arginine (which is conditionally required for children). These values are similar to those found in the analysis of amino acid profile of soya milk produced from three different processes (Ogo et al., 2018). Thus a combination of these cheap and accessible food items in the right form and appropriate preparation methods may be helpful in the fight against malnutrition such as proteincalorie malnutrition, which has led to increased mortality rates particularly in developing countries where healthcare services are suboptimal. Worthy of note is the consistent higher amount of leucine found in all the samples, a result that is congruent with those of Ogunlade (2015). Leucine has been shown to influence insulin signaling pathway and may be a potential candidate for the management of obesity and 
metabolic syndrome (Layman et al., 2006). The present study also revealed that lysine, the most limiting amino acid in cereals is found in appreciable amounts in all samples of tiger nut analysed and thus may be useful in supplementing diets that primarily depend on consumption of cereals. It is also important to note that the low amount of tryptophan found in all the samples analysed, which range between 0.3 to just a little over $1 \mathrm{~g} / 100 \mathrm{~g}$ is in consonance with report of study that evaluated the amino acid profile of milk preparation from tiger nut (Salau et al., 2013). Tryptophan is a precursor of a neurotransmitter serotonin that helps in mood elevation. Consequently, people that often consume this product may need supplementation to meet the required daily allowance needed to enhance quality sleep (particularly for people with cases of insomnia) and good mood and in management of depression and anxiety. Glutamic acid appeared consistently higher in all samples than other amino acids, making these products ideal for consumption by athletes and other body building sportsmen.

\section{Conclusion}

The present study clearly revealed that tiger nut is nutritionally rich. The misconception that shrouds the consumption of dried food items particularly of fruits and in this case, tiger nut has been addressed as shown by retention of significant amounts of amino acids in dried tiger nut powder and higher carbohydrate content compared with fresh tiger nut products. Such conclusion is apt in order to give well informed nutritional advice aimed at optimizing the nutriture of a particular food item. Furthermore, the high content of protein in these preparations make it suitable for management of protein energy malnutrition as an integral part of care and support of patients.

\section{References}

Abaejor, R., Djomdi, I. and Ndojouenkeu (2006). Characteristics of tiger nut (Cyperus esculentus) tubers and their performance in the production of a milk drink. J. Food Process Preservatives. 30;145-163

AACC international (2010). Approved method of analysis, $11^{\text {th }}$ edn. (On-line) AACC international, st Paul, MN

Abano,E.E and Amoah,K.K.(2011).effect of moisture content on the physical properties of tiger nut(cyperus esculentus)

Adejuyitan J.A., (2011). Tiger nut Processing: Its food uses and health benefits) Amerian Journal of Food Technology 6(3):197-201
Adel, A.A.M, Awad. A.M, Mohamed, H.H and Iryan, S. (2015). Chemical composition, physichochemical properties and fatty acid profile of tiger nut (cyperus esculentus) seed oil as affected by different preparation methods. International Food Research Journal 22(5): 1931-1938

Adejuyitan, J.A., Otunola, E.T., Akande, E.A., Bolarinwa, I.F. and Oladokun, F.M. (2009). Some physiochemical properties of flour obtained from fermentation of tiger nut (cyperus esculentus) African Journal of food science, 3:51-55

AOAC (2005). Official Methods of Analysis (18th edition) Association of Official Analytical, Chemists International, Maryland, USA.

Bamishaiye, E.E., and Bamishaiye, O. M. (2011). Tiger nut: as a plant, its derivatives and benefits. African journal of food, Agriculture, Nutrition and Develpoment. 11(5), 5157-5170

Belewu M.A. and Abodunrin (2006) preparation of kunnu from unexploited rich food tiger nut (cyperus esculentus). World Journal of Dairy and Food Sciences, 1:19-21

Chukuma,E.R., Obiama, N.and Christopher ,O.I.(2010). The phytochemical compostion and some biochemical effect of Nigerian tiger nut (cyperus esculentus) tuber. Pakistan Journal of Nutrition 9(7); 705-715

Gambo, A and Da'u, A (2014). Tiger nut (Cyperus esculentus): composition, uses and health benefits - a review. Bayero Journal of Pure and Applied Sciences 7(1); 56-61

Jing Si-qun, Ebeydulla Rahman, Zheng-hui Chen and Yao-Xiang Wang (2016). Nutritional profiles of tiger nut (Cyperus esculentus) plant organs during its growth cycle. African Journal of Biotechnology 15(22); 1050-1057

Ogo, A.O, Amali E.O.O, Efiong E.E., Gbaa A. and Enenche D (2018). Optimising soymilk protein nutriture through selection of appropriate processing technique. Nigerian Journal of Pure and Applied Sciences.

Ogunlade, I., Adeyemi B.A. and Aluko O.G (2015) Chemical compositions, antioxidant capacity of tiger nut (Cyperus esculentus) and potential health benefits. European Scientific Journal Special edition pp 217224

Okafor, J. N.C Mordi, J. O., Ozumba, A. U., Solomon, H.M., and Olatunji, I. (2003). Preliminary studies on contaminations in tiger nut (yellow) variety. In the proceedings of the $27^{\text {th }}$ annual conference, 
Nigerian institute of food science and technology, $13^{\text {th- }} 17^{\text {th }}$ oct $210-211$

Okorie S.U and Adedoku 1.1(2013). Effect of partial substitution of fresh cow milk with bambarnut milk on nutritional characteristics and yield of soft (unripe) cheese -'warankshi' advance journal of food science technology 5(6): 665:670

Oladele, A.K., and Aina, J.O. (2007). Chemical composition and functional properties of flour from two varieties of tiger nut. African journal biotechnology, 6, 2473-2476

Oldfield, Callie A; Evans, Jonathan P. (2016-3$01)$. 'Twelve years of repeated wildhog activity, promotes population maintenance invasive clonal in a coastal dune ecosystem' ecology and evolution: n/a-n/a-ISSN 20457758 doi: 10.1002 /ece 3.2045

Peter Taiwo Olagbemide \& Tolulope Adeola Ogunnusi (2015). Proximate analysis and chemical composition of tiger nut. European Journal of advanced research in biological and life sciences 3(3): 1-10
Rita ES (2009). The use of tiger nut (cyperus esculentus), cow milk and their composite as substrate for yoghurt production. Pak.J. NUTR., 6:755-758.

Salau, R.B., Ndamitsto, M.M., Paiko, Y.B., Jacob, J. O., Jolayemi, O.O., and Mustapha, S. (2012). Assessment of the proximate composition food functionality and oil characterization of mixed varieties of cyperus esculentus (tiger nut) rhizome flour. Continental J. Food Science and Technology 6(2); 13-19

Salau R. B., Aminu M., Bisiriyu M.T., Bamidele K.G and Bashir U (2013). Evaluation of Amino Acids in the Milk Preparations from Tiger Nut Rhizome and its Mixed Varieties. Journal of Pharmacy and Biological Sciences 7(5); 15-19

Udeozor, L.O (2012). Tiger nut-soy milk drink: preparation, proximate composition and sensory qualities. International Journal of Food and Nutrition Science vol 1(4) pp1826 